\title{
Crossing the Borders of Teaching English with the Help of Band of Brothers
}

\author{
Attila IMRE \\ Sapientia Hungarian University of Transylvania (Cluj-Napoca, Romania) \\ Department of Applied Linguistics \\ attilaimre@ms.sapientia.ro
}

\begin{abstract}
The present article discusses the popularity of English since World War II, which has turned to a decisive lingua franca in Europe over the past decades and has been a major component of the thriving language industry. Our hypothesis is that when it comes to teaching foreign languages, most notably English, the inclusion of translation is rather limited (at least in Eastern Europe), and translation is even "stigmatized and excluded" from instruction (cf. Venuti 2013). However, multimedia products from the USA, most notably Hollywood movies, are highly popular among teenagers thus, we argue for the benefits of watching (together with their scripts and subtitles) and using them as "natural" sources of language which may be used to counterbalance the textbooks and grammar books originating from the UK. We exemplify specific grammar- and vocabulary-related border crossings of institutionalized language teaching (e.g. Subject-Verb disagreement or double negative) from Band of Brothers, a highly popular TV mini-series. We also highlight the importance of the target language and individual norms when translating or subtitling taboo words. The conclusion section mentions the effectiveness of translations through subtitles, knowing that the effort is diminished when learning and entertainment is combined (cf. Caimi 2006) in the hope of serving the real needs of the learners.
\end{abstract}

Keywords: teaching English, Band of Brothers, subtitles, non-standard grammar, language use and norms.

\section{Introduction}

Teaching English in Europe is a thriving business at present. However, its popularity started after World War II, as Anderman states: "While during the first half of the twentieth century the first foreign language learned by European youths was French, four fifths are now learning English and only a fifth are learning French" (Anderman 2000: 48-49, based on Walker 1997). 
A different source, Language International, refers to English as "increasingly becoming the world's lingua franca" as early as 2001, even if "the study of foreign languages has suffered" and "the need for language proficiency has grown" ("The Trouble with English ..." 2001: 6).

More recently, we have reports proving the growth of the language industry within the European Member States, reaching "an estimated value of ... 8.4 billion $€$ for 2008", comprising "translation, interpreting, software localisation and website globalisation, language technology tool development, language teaching, consultancy in linguistic issues and organisation of international conferences with multilingual requirements" (Rinsche and Portera-Zanotti 2009: 3). However, it is more interesting that the authors have estimated a growth rate of $10 \%$ for the next years, predict that the language industry in Europe may reach 16.5 billion $€$ by 2015 , and they add that the language industry "seems to be less affected by the financial crisis than other industry sectors" (2009: 3).

While these figures are encouraging, we have to admit that language efficiency in East-Central Europe is typically lower than in other parts of the continent due to multiple reasons (i.e. politics, economy, geography). Although we cannot deal with it extensively in the present article, we should mention the (more or less) typical case scenario over the past three decades:

- English, German, Spanish, French, and Italian "continue to be the most widely used languages throughout Europe" (Rinsche and Portera-Zanotti 2009: 5);

- English textbooks from Cambridge and Oxford (UK) "invaded" Eastern European countries, and the majority of teachers have been encouraged (partnerships, projects, the British Council) to "use" British English (BE, UK English);

- these textbooks have been further supported by grammar books published and popularized by the aforementioned publishing houses and others based in the UK (Macmillan, Longman), while English teaching material published in Europe mostly relied on them, favouring British English culture, grammar, vocabulary, and spelling;

- the Common European Framework of Reference for Language (CEFR) within the Council of Europe promotes "methodological innovations and new approaches to designing teaching programmes", ${ }^{1}$ facilitating an English close to British English, focusing on developing reading, speaking, listening, and grammar skills, which are later evaluated on a scale (six levels, A1 - the lowest, A2, B1, B2, C1, C2), aiming at successful oral and written communication. School, university, and language centre curricula have been elaborated to support this vision.

Our preliminary hypothesis is that the inclusion of translation in teaching foreign languages in Eastern Europe is rather limited if existing at all. As for

1 https:/www.coe.int/en/web/common-european-framework-reference-languages/leveldescriptions, 13 September 2018. 
English, the majority of textbooks and grammar books originate from the United Kingdom, and the publishers do not invest in "localizing" them by including English-native language translation exercises. Venuti offers a harsh but convincing explanation:

Translation has encountered the disciplinary resistance ..., first of all, because it runs counter to institutionalized practices in foreign-language instruction. Since the late 1960s, the most prevalent form of foreignlanguage pedagogy has been "direct communication" or "total immersion," in which the goal of native proficiency leads to the suppression of any teaching methods that might require the student to rely on the mediation of English. Consequently, translation has been stigmatized and excluded as a method of foreign-language instruction, even though it served precisely this purpose for centuries. (Venuti 2013: 62)

However, present-day teaching of English should rely on all available modern means, among which we can highlight the popularity of multimedia products. As we know, they mainly belong to the entertainment industry and are mostly designed and produced in the USA: movies and TV series from Hollywood as well as various video games, reaching global popularity among youngsters. The effects can be easily traced in schools and university courses when the majority of more fluent speakers of English (the so-called Generation Z) ${ }^{2}$ confess that they are regular and heavy consumers of these products, even if they do not know advanced English (grammar) in its "institutionalized" form. Knowing these facts, Cronin's remark is beyond any doubt: "contemporary students have a strikingly highly developed audio-visual literacy from an early age" (Cronin 2009, Introduction, xi). This is further supported by the fact that operating systems (Windows, Mac, or Linux) are set to US English by default, completed with the Microsoft Office software package, which - again, by default - starts with English (United States) speller and proofing tools unless purchased locally.

In our view, the issues and facts listed above should be considered if we have in mind the successful teaching of foreign languages, most notably English. We are more than sure that there is a great discrepancy between the present-day "multimedia", English (or "McEnglish") and the English available in textbooks and grammar on the European market, which is mostly levelled by a certain global English that East-Central European citizens get in touch with during their travels and journeys abroad. In this respect, another important observation should be considered:

English was judged to be the language of film, it was 'good, spontaneous, cool,' whereas other European languages were considered unattractive

2 http://socialmarketing.org/archives/generations-xy-z-and-the-others/, 13 September 2018. 
or unsuitable. The fact that most of the teenagers surveyed were learning English facilitated their enjoyment of Hollywood films and this provided a further incentive for learning the language. The charmed circle of language acquisition and cultural prestige was thus very much in evidence. (cf. Meers 2004: 167-169, cited in Cronin 2009: 14).

While the above quotation expresses the conclusion of Meers regarding speakers of Flemish, we have had the chance to observe a similar attitude among Hungarian and Romanian teenagers as well. However, once including movies among the teaching resources, we are also faced with translation through the subtitles unless the dubbed version is chosen (which may still contain cultural elements even without linguistic challenges).

We firmly believe that a successful real-life communication in English should include original English movies, focusing on both the original subtitle and its possible translation in the form of native-language subtitle. Of course, this should not replace but complete the English found in textbooks and grammar books. Although the use of movies might be distressing for beginners or intermediate learners, it is worth considering Heltai's encouragement in this respect:

... teaching English to students of agriculture[,] I had found that they had little difficulty in translating what I regarded as difficult technical texts, even though their linguistic competence was limited. Texts of a more general type, however, mainly from international organisations such as FAO, which contained only a minimal number of technical terms and which I myself understood without any difficulty, posed a much more serious challenge to them both in decoding and re-encoding (Heltai 2000: 34)

The quote demonstrates that learners may prove to be much more efficient than teachers might expect, and even if Heltai makes this observation referring to technical texts, we can adapt it to movie subtitles, relying on their audio-visual literacy (cf. Cronin above).

English subtitles may offer multiple benefits as, while trying to understand and translate it, attention must be paid to lexicon, syntax, and "patterns of meaning, and not only on denotation and connotation, but also on dialect and register, style and genre, intertextuality and intercultural relations" (Venuti 2013: 165). In the following, we will offer ideas how movies may be included in the course of teaching, exemplified with a popular TV series. 


\section{Crossing borders by watching Band of Brothers}

The benefits of watching TV series is manifold: expanding vocabulary (and grammar), perfecting pronunciation, direct access to US English, which successfully completes the mainly UK English textbooks and grammar books, and a simple search among the highest-rated TV series, shows or documentaries or most popular ones ${ }^{3}$ offers plenty of material for self-study. These productions may be accessed in original English with English subtitles, then compared to native language subtitles. Furthermore, teachers may indeed become popular with these TV shows, making learners focus more on the material, and "homework" assignment may be varied. For example, homework assignments occasionally may consist of the following:

- Creating an Excel file with specific words (terms, difficult ones, new ones, non-standard ones, etc.);

- Copying/memorizing favourite sentences, stock phrases, idiomatic expressions;

- Hunting for poor translations/improving them;

- Creating individual sentences from 3-5 collected words and/or organizing a group quiz.

- Last but not least, a group vote may be cast to find out the most popular TV series learners follow and debates may be organized arguing for or against some/ all of them (Game of Thrones, Harry Potter, The 100, etc.).

As Band of Brothers is among the top rated TV series, it may be used in the initial stage, selecting those parts that may be relevant in supporting the textbook material; for instance, when teaching tenses or conditional sentences, learners may collect sample sentences from the series, then have them translated and compared with the native language subtitle. As movies "are always popular sources of foreign language teaching materials, and there is no doubt that they are valuable tools for general unintentional language acquisition" (Caimi 2009: 247), the learners' success is assured, and - depending on their level of study - they may be interested in further language-related possibilities of subtitles: discussing the theme of the film, recognizing different registers, or appreciating the storyline (Caimi 2009: 248).

Thus, if we move along the same path, we reach Tveit's seminal remark: "subtitling has an important educational value" (Tveit 2009: 93). The argument is amply described, stating that Scandinavian countries know English better due to the pedagogical value they attribute to the original English language soundtracks, concluding that "listening comprehension was perceived as significantly more difficult by students from 'dubbing countries' than by students from 'subtitling countries', the former category showing a much stronger need for an increased

3 https://www.imdb.com/chart/tvmeter, 14 September 2018. 
knowledge of vocabulary when communicating in English" (Tveit 2009: 93). As movies with subtitles offer the soundtrack, the image, and the script, we believe that this is an "enhanced" version of soundtracks.

While Tveit associates subtitling with education, Petrocchi discusses the advantages of pedagogic translation, which includes translation "considering that its purpose is to teach a language" (2006). In the following, we would like to offer grammar-related samples from Band of Brothers with this pedagogical or educational intention, even if they cross the border of formal education.

\section{Crossing a few grammatical and vocabulary borders in Band of Brothers}

While some teachers may completely disregard or banish audiovisual sources during teaching foreign languages, the majority of them possibly applies subtitled movies and shows "as an intermediate position between spontaneous exposure in natural settings and formal instruction" (Caimi 2009: 246). Our examples below come to support the "natural settings", knowing that this should be included in the curriculum only after covering the formal part; yet we consider both parts relevant in a successful teaching course, detailed in the following.

The overwhelming majority of textbooks and grammar books offer only standard samples for non-native speakers of English, among which we can mention sentence structure, the way interrogatives and negatives are formed, excluding the double negatives, etc. Our basic idea is that these tend to be artificial, otherwise students would not ask a teacher after years of study about the difference between I am going to or I'm gonna, to mention but an example.

Once learners are familiar with "standard" grammar, they "can reach higher level of translation and, vice-versa, by translating they acquire more competence in the knowledge of grammatical structures", as Petrocchi concludes (2006). Nevertheless, many learners keep complaining about grammar, as described vividly by Lewis:

Many children beginning a foreign language at school find it exciting and fun. Sadly, after studying the language for a while, many find it one of the less attractive subjects of the school timetable. There is some research evidence that if the children themselves are asked which bit of the language lesson they like least, they usually reply "Grammar!" (Lewis 1986: 12)

Knowing that this generation of pupils and students are eagerly following many TV series, we opted for a TV mini-series, Band of Brothers, ${ }^{4}$ which is 
based on Ambrose's book, (2001b, $1^{\text {st }}$ ed. 1992) and is second in the Top Rated TV Shows, ${ }^{5}$ even ahead of Game of Thrones. Choosing this TV mini-series has multiple advantages:

- It is based on a previously written book, which has been translated into many languages.

- The original English subtitle may be compared to many native language subtitles.

- The English book version and the English transcript may be compared both factually (for instance, the appearance of product placement in the series: Ford or General Motors) and linguistically (grammatical and vocabulary differences).

After having watched the series, we created a database of almost 1,000 entries connected to military culture, military terminology, and the language soldiers use, differentiating several subcategories. In the following, we offer a few samples from the database, which all break the rules of "standard" grammar teaching, yet they are relevant enough for intermediate or advanced learners to be familiar with.

In our case, crossing the borders of teaching English means counterexamples for grammatical rules (e.g. third person singular - $(e)_{s}$ in present tenses), for which we were able to detect at least two or three examples from the subtitle, detailed in the sections below.

The rationale behind this is to make learners aware of the fact that these "deviations" from standard language are somewhat normal and acceptable in particular contexts, and learners might find it amusing to spot non-grammatical instances in a native speaker environment.

\subsection{Subject-Verb disagreement}

In the initial stage of teaching standard English sentences, learners are expected to produce utterances containing both a subject and a predicate, completed with a so-called Subject-Verb agreement (third person singular verb always takes an -s or -es in all present tenses; was and were in Past Simple and Continuous).

The deviation from this rule is severely punished by teachers in the initial stage of learning, for obvious reasons. The question is whether learners will ever be faced with samples we collected from Band of Brothers $(B o B)$ :

1) That Louie don't even have a weapon. (E02, 16:26)

2) ... it don't matter. (E01, 35:10)

3) So I says, (E01, 00:53)

4) ... the Lieutenant don't drink. (E02, 45:16)

5) You know, you was... (E10, 24:34)

6) We was attacked ... (E01, 00:27) 
This is probably one of the most striking/visible grammar issues, and - at least at intermediate or advanced level - learners should be acquainted with nonstandard English grammar as well, not to encourage their use but to accept them as existing variants.

\subsection{Interrogative forms}

Another important aspect of English grammar is the formulation of interrogative forms, paying a special attention to auxiliary verbs preceding nouns (Do you like Shrek?; Where did Shrek meet Fiona?). However, BoB offers counterexamples as well:

7) They didn't try to cross the river? (E08, 15:40)

8) What, you can't see? (E03, 24:01)

9) I should rub it? (E08, 22:44)

Of course, there are various explanations for these examples, ranging from lack of education, regional variants to mocking foreigners, but once again, these forms are real-life examples.

\subsection{Question tags}

Question tags signal an important difference even between Indo-European languages (such as English and Romanian), while comparing English and Hungarian in this respect also offers interesting remarks.

While English typically formulates question tags based on the Subject and the auxiliary verb (Shrek is cool, isn't he? You didn't see "Titanic", did you?) with a few extra remarks (e.g. special cases with certain pronouns, singular/plural), "nongrammatical" solutions are typically banished from classes (e.g. ..., right?, ... ehm?).

Let us see a different type of non-grammatical type of question tag from $B o B$ :

10) Makes quite a target, don't he? (E04, 27:02)

11) New Jersey, huh? (E10, 51:11)

12) Happy hour, huh? (E01, 07:10)

13) Well, you gotta try, huh? (E03, 22:36)

14) Twenty-two wounded, huh? (E05, 25:04)

Example 10 offers a further case of Subject-Verb disagreement discussed in Section 3.1, while examples 11-14 offer solutions for slang versions of question tags.

\subsection{Elliptical sentences}

Ellipsis (together with substitution) is a challenging subject in English syntax, but first let us remember the definition of ellipsis we enjoy the most: "in ellipsis, 
an item is replaced by nothing" (Baker 2011: 196), and the definition is vague enough to include any part of the sentence: Subject, Verb, or other parts.

There are various reasons to use elliptical structures, some of which - connected to $B o B$ - are listed below:

- little time to expand ideas; in the heat of attacks and defence manoeuvres change of information must be brief, without affecting comprehension;

- the special setting turns ellipsis a desirable procedure as transcripts must be short enough to fit into lines of limited characters; according to the $B B C$ Online Subtitling Editorial Guidelines, a subtitle line should contain "roughly 32 or 34 characters per line" (Ford Williams 2009: 13); we have the same recommendation in the ITC Guidance on Standards for Subtitling ("ITC Guidance on Standards for Subtitling" 1999), while Amara, the award-winning online subtitle platform for TED Talks recommends fewer than 42 characters per line; ${ }^{6}$

- military culture leaves plenty of room for casual, friendly conversation typical among comrades, full of slang (Looey), abbreviations (sarge), acronyms ( $A W O L$ ), and ellipsis (all with the purpose of shortening communication), which hardly resembles the academic verbosity of educated people.

The instances found in $B o B$ are worth categorizing into the following groups:

a) ellipted Subject (although grammar books allow this only in case of imperatives or elevated style of writers and poets):

15) Doesn't matter. (E10, 32:15)

16) Don't know. (E07, 07:05)

17) Makes quite a target, don't he? (E04, 27:02)

18) Must have liked that hospital. (E08, 06:34)

[So you come from the hospital?

Yeah.

Must have liked that hospital, because we left Holland four months ago.]

When ellipsis is used, the only important requirement is recoverability so that the information could remain fully clear. In examples 15-18, the missing Subject may be recovered easily either from the sentence or the larger context (e.g. Example 18, square brackets);

b) ellipted Predicate:

19) He out of high school. (E08, 14:25)

The fact that only one instance was found reflects that content verbs are vital in exchange of information, and we suspect that Example 19 was found because the strong verb be may be easily recovered or the place adverbial may indicate that the missing verb is drop.

c) ellipted auxiliary verb:

20) [HAS] Anybody ever heard of a little joint called Lulu's? (E04, 27:02)

21) Hey, guys, [IS] this taken? (E08, 13:04)

6 https://support.amara.org/support/discussions/topics/28857, 21 June 2017. 
22) How many points [DO] you need? (E10, 22:19)

23) ... how you [ARE] doing? (E02, 23:57)

24) $I$ [HAVE] swum across the Niagara once. (E07, 19:11)

25) [ARE] You alone? (E03, 04:59)

26) [HAVE] You seen Lt. Meehan? (E02, 26:03)

The examples clearly show that any auxiliary verb may be ellipted, and not necessarily at the beginning of the sentence. Most interesting are examples 24 and 26, as learners might need some extra time to discover that they are not incorrect Past Simple uses as they express life experience or result, characteristic to Present Perfect Simple.

d) ellipted Subject and auxiliary verb:

27) Been finding camps like this all over the place. (E09, 49:40)

28) Coming, Perco? (E08, 23:42)

29) Gonna take everybody's word. (E03, 28:43)

30) Think I overdid the cover for my foxhole? (E07, 35:49)

e) ellipted adverb:

31) Long as we have to. (E04, 24:03)

f) ellipted conjunction:

32) [IF/IN CASE] You see any, let us know. (E04, 23:58)

g) elliptical sentence:

33)You men going on patrol ... nothing rattles, nothing shines, no helmets.

(E08, 29:12)

The most laconic complex order in the entire $B o B$ is probably expressed by Example 33, in which half of the sentence is missing (You men, who are ...), followed by a succession of three elliptical prohibitive orders.

\subsection{Contracted forms}

Grammatical contractions are regularly taught during English classes, although the ain't form is usually banished. $B o B$ contains no fewer than 35 instances of this form (including 3 ain't gonna structures), so we tend to think that teachers should cross the border in this respect as well. A few examples are presented below:

34) Oh, that dog just ain't gonna hunt. (E01, 39:49)

35) Five of us ain't gonna secure a road. (E04, 23:58)

36) You gotta realize it ain't about you. (E02, 22:07)

37) Ain't you Sink's jeep driver? (E02, 28:38)

It is also worth mentioning that even if we use Microsoft Office Word 2016 for drafting this article set to English (United States), the spelling and proofing tools will underline in red all the ain't forms (mostly replacing them with isn't and aren't) as well as the gonna or gotta, considering them informal or non-standard; similar remarks about gonna and gonna are found in printed and online dictionaries as well. 
The Shorter Oxford English Dictionary describes gonna as "non-standard, [Repr. a pronunc.]" (Trumble and Stevenson 2002: 1124) and gotta as "colloquial [Repr. a pronunc.]" (2002: 1130), while the online Oxford English Dictionary labels them as "informal". ${ }^{7}$ Yet, they are rather frequent options for the 'going to' and 'have (got) to' structures, predominantly in oral conversation; however, we are more than sure that Generation $\mathrm{Z}$ uses these forms rather frequently while chatting online as well.

Other contractions have also been added to the database (guy'd have to march, people'd, Krauts'll, y'all), mainly rendering oral conversations and signalling that not only personal pronouns may be followed by the contracted would and will, while y'all is regional (Southern) US English. ${ }^{8}$

\subsection{Double negatives}

Double negatives in English are typical "mistakes" made by beginners resulting, for instance, from perfectly legitimate double negatives in Romanian and Hungarian translated word for word; these are rather seriously frowned upon during the teaching phase; ${ }^{9}$ yet, it is a sheer fact that native speakers of English use this structure, even in $B o B$ :

38) Don't give him no excuses. (E01, 10:48)

39) I can't see nothing. (E02, 30:53)

40) Old Gonorrhea don't miss nothing. (E04, 05:47)

Of course, teachers may not accept all these constructions from non-native speakers as correct. Yet, they may be accepted from time to time and explained that there is a "more standard" option, preserving the element of fun, which inevitably happens when non-native speakers foreign to regional speech struggle hard to "adapt". This may be observed in the famous movie entitled Snatch, containing slang terms used by Irish Gypsies. ${ }^{10}$

\subsection{Conditional sentences}

Similarly to double negatives, there are rather strict rules for beginners and even intermediate learners concerning conditional clauses. Teachers typically present three "basic" types completed with three more (the so-called "zero" conditional lacking will in the main clause of Type I and two more mixed conditionals). However, the use of would in the if-clause is usually banned until upperintermediate level as learners may get confused regarding modal and non-modal uses of would. Let us see three examples from $B o B$ :

7 https://en.oxforddictionaries.com, 14 September 2018.

8 https://www.collinsdictionary.com/dictionary/english/yall, 14 September 2018.

9 The author of the present article constantly experiences this in East-Central Europe.

https://www.imdb.com/title/tt0208092/, 14 September 2018. 
41) I was beginning to wonder if any of us would make it through at all. (E07, 49:37)

42) I wondered if people would know what it cost the soldiers to win this war. (E08, 54:55)

43) Even if they would, who'd I put in his place? (E07, 15:35)

While Examples 41 and 42 contain wonder suggesting a polite formulation, there is still an air of uncertainty about Example 42 (why not use knew?). Example 43 is rather unclear in this respect, leaving us wonder whether a "more standard" version (e.g. did) should be applied here.

The slight nuances expressed by modal verbs is one of the most problematic issues of English grammar, where Lewis's excellent approach might have helped a lot over the past three decades but for complete disregard from other authors of English grammars and textbooks. It is Lewis who introduces the concept of remoteness, which may be applied to modal "pairs" such as can-could or willwould, further arguing that this remoteness may be temporal, social relationship, likelihood, etc. (Lewis 1986: 99-109).

It is alarming that many English teachers still describe would as the 'past' form of will, not to mention that even dictionaries display modal verbs among the irregular verbs (Magay and Országh 1993). As we cannot delve into details regarding modal verbs (let alone their combination with other grammatical structures, such as conditionals, passive voice, or reported speech), suffice it to say that it is a grammatical category that should be dealt with both extreme care and flexibility.

\subsection{Taboo words}

In the process of teaching English, crossing vocabulary borders is typically easier than grammatical ones as texts containing slang terms are included in textbooks. Nevertheless, a rather discomforting area may be the use of taboo words.

Hollywood productions (but not exclusively) relentlessly use some of the taboo words, which usually causes trouble when translated or subtitled into the notoriously bashful Romanian (cf. Ro. la naiba 'damn' or 'dammit', which seems to be the joker term for all curse words). Hungarian translations and subtitles used to be - until recent past - more daring on the one hand (e.g. translating genitals) and more restrained on the other hand (e.g. mostly using first-name terms, then addressing formally in subtitles). ${ }^{11}$ We tend to think that sometimes crossing the border of "educated language" results in a more lifelike situation, but there is no recipe for that, even if there is a card game in Romanian to "tackle" taboo words. ${ }^{12}$

11 Cf. TED presentations, but even the subtitles of present-day TV series such as Perception.

12 We have come across a relatively new Romanian card game on the market containing more than 1,000 taboo words (recommended age: 13+), https://noriel.ro/joc-taboo-ghiceste-cuvantul, 14 September 2018. 
The lack of clear guidelines for translators and subtitlers in this respect is exemplified in the table below containing the most popular taboo word on Facebook (collected in only 3 days) ${ }^{13}$ and its occurrence in Band of Brothers:

Table 1. Taboo words on Facebook and in Band of Brothers

\begin{tabular}{|c|c|c|c|}
\hline & En. (shit) & Hu. (szar) & Ro. (rahat) \\
\hline Facebook & 10.5 million & - & - \\
\hline$B o B$ book & $\begin{array}{c}15 \\
\text { (Ambrose, } \\
\text { 2001a) }\end{array}$ & $\begin{array}{l}\mathbf{2 0} \\
\text { (Ambrose 2001a) } \\
\text { Transl. Gy. Molnár }\end{array}$ & $\begin{array}{c}11 \\
\text { (Ambrose 2010) } \\
\text { Transl. N-D. Cetină }\end{array}$ \\
\hline $\begin{array}{c}B o B \\
\text { subtitles }\end{array}$ & 68 & $\begin{array}{c}14 \\
\text { (Miklós Vincze, } \\
\text { SDI Media Hungary) }\end{array}$ & $\begin{array}{c}7 \\
\text { (Alexandru Gheorghia, } \\
\text { SDI Media Group) }\end{array}$ \\
\hline
\end{tabular}

The different numbers reveal that the subtitlers tried to reduce taboo words to the minimum, respecting certain language and translation norms (cf. Klaudy 2003: 34). In the case of subtitles, we have to reiterate again that "it is not the words themselves which necessarily determine the communicative function of a statement, but the way they are given expression; their relationship to tone of voice, body language and situation” (Skuggevik 2009: 205), which probably explains why Romanian and Hungarian subtitles contain much fewer taboo entries than the English script. The choice is obviously influenced by the type of media (the book version contains more actual words, stemming from diaries of soldiers) and individual translation strategies (cf. Klaudy 2003: 175) combined with the present trends of the target culture.

Ultimately, the aim of language learners is "to pass themselves off as native speakers of the language they are learning", and "phonetic exercises of various kinds (implicit or explicit)" are part of "language teaching methods" (Cronin 2009: 120). However, this also means that beyond the knowledge of words it is equally important to be aware of "language use", as Cronin concludes. In our view, this is perfectly feasible with the help of well-selected movies, TV series and shows, together with their subtitles.

\section{Conclusions}

The present article may be considered highly idealistic, trying to argue for the importance of translation as a teaching/learning strategy which may be applied to analyse (and create) subtitles for Hollywood productions, knowing that English is (still) among the most popular languages in Europe.

13 https://www.adweek.com/digital/popular-profanity/, 25 July 2018. 
This popularity means - among others - that studying English is easily and cheaply available at all levels and for multiple purposes. Thus, learners may equally contribute to the success of the teaching and learning process provided the teacher is ready to cross one more border: the status of the teacher turning to a partner in a world where multimedia chokes us all and can offer guidelines to survive with less effort than if tried alone. This is more than welcome as it may reduce the learning curve.

Mastering the so-called standard (UK or US) English is more difficult than it may seem at first sight because non-native speakers should never judge native speakers regarding their way of speaking (cf. double negatives), yet it does not mean that imitating them is void of complications; after all, it would be awkward to use double negative during a Cambridge Advanced English exam in Romania, but it would be perfectly natural for a non-native speaker living in a community where double negative is used on a regular basis. As illustrated in examples 3.13.8, formal teaching may be interestingly combined with authentic and "natural" (i.e. substandard) linguistic manifestations.

We do not claim that it is always easy to find the proper boundaries and balance between formal and informal, but teachers should try to distance from the comfort zone of textbooks and grammar books as well as limit their dominance; native English authors publishing textbooks often present grammar and vocabulary issues only from their perspectives, with little localization or tailoring the book to the specific needs of a non-native language community.

Hence we argue for the necessity of textbooks and grammar books containing translation-related practice from English to native language and vice versa. After all, "translation can be a useful tool and an effective method to learn a language" (Petrocchi 2006), but translations offer even more than that by producing "effects that exceed a lexicographical equivalence and work only in the translating language and culture" (Venuti 2013: 169).

It has been also observed that " $[w]$ hen language learning and entertainment are combined, students are highly motivated and likely to enjoy the video without paying attention to the effort involved in understanding a foreign language" (Caimi 2006: 96).

Today, when the importance of global communication is emphasized worldwide, certain border crossings happen all over, and it is the teachers' responsibility and will to tailor the English taught to the real needs of the learners, whatever the level. However, it is certain that this border extends far beyond the covers of textbooks and grammar books, amply exemplified with samples from Band of Brothers. 


\section{References}

Ambrose, Stephen E. 2001a. Az elit alakulat (Band of Brothers). Transl. by György Molnár. Budapest: GABO.

- 2001b. Band of Brothers: E Company, 506 $6^{\text {th }}$ Regiment, 101 ${ }^{\text {st }}$ Airborne from Normandy to Hitler's Eagle's Nest. $2^{\text {nd }}$ edition. New York \& London: Simon \& Schuster.

— 2010. Camarazi de Război (Band of Brothers). Transl. by Nicolae-Dan Cetină. Târgu-Mureş: Sebastian Publishing House.

Anderman, Gunilla. 2000. A global language for the global village? A response to Mary Snell-Hornby. In Schäffner, Christina (ed.), Translation in the Global Village, 47-50. Clevedon: Multilingual Matters.

Baker, Mona. 2011. In Other Words. A Coursebook on Translation. $2^{\text {nd }}$ ed. Routledge.

Caimi, Annamaria. 2006. Audiovisual translation and language learning: the promotion of intralingual subtitles. The Journal of Specialised Translation 6: $85-96$.

— 2009. The teaching/learning perspective: Subtitling in second language acquisition. In Díaz Cintas, Jorge-Anderman, Gunilla (eds), Audiovisual Translation. Language Transfer on Screen, 240-251. Palgrave Macmillan.

Cronin, Michael. 2009. Translation Goes to the Movies. London and New York: Routledge.

Ford Williams, Gareth (ed.). 2009. BBC's Online Subtitling Editorial Guidelines V1.1. London: BBC.

Heltai, Pál. 2000. Translating official texts from English into Hungarian. In Dróth, Júlia (ed.), Szaknyelv és szakfordítás. Tanulmányok a Szent István Egyetem Alkalmazott Nyelvészeti Tanszékének kutatásaiból 1999-2000, 34-49. Gödöllő: Szent István University.

Klaudy, Kinga. 2003. Languages in Translation. Budapest: Scholastica.

Lewis, Michael. 1986. The English Verb: An Exploration of Structure and Meaning. Hove: Language Teaching Publications.

Magay, Tamás-Országh, László. 1993. Magyar-angol kéziszótár. Budapest: Akadémiai Kiadó.

Meers, Philippe. 2004. 'It's the language of film!': Young film audiences on Hollywood and Europe. In Stokes, M.-Maltby, R. (eds), Hollywood Abroad: Audiences and Cultural Exchange, 158-75. London: British Film Institute.

Petrocchi, Valeria. 2006. Translation as an aid in teaching English as a second language. Translation Journal 10(4). http://www.bokorlang.com/ journal/38teaching.htm. (Last accessed: 14 September 2018). 
Rinsche, Adriane-Portera-Zanotti, Nadia. 2009. Study on the Size of the Language Industry in the EU. Studies on Translation and Multilingualism. Surrey: European Commission-DGT.

Skuggevik, Erik. 2009. The teaching/learning perspective: subtitling in second language acquisition. In Díaz Cintas, Jorge-Anderman, Gunilla (eds), Audiovisual Translation. Language Transfer on Screen, 197-213. Palgrave Macmillan.

Trumble, William R.-Angus Stevenson (eds). 2002. The Shorter Oxford English Dictionary. $5^{\text {th }}$ ed. Vol. I. A-M. Oxford: Oxford University Press.

Tveit, Jan-Emil. 2009. Dubbing versus subtitling: Old battleground revisited. In Díaz Cintas, Jorge-Anderman, Gunilla (eds), Audiovisual Translation. Language Transfer on Screen, 85-96. Palgrave Macmillan.

Venuti, Lawrence (ed.). 2013. Translation Changes Everything. Theory and Practice. London and New York: Routledge.

Walker, D. 1997. The British Empire is dead: Long live the British Empire. The Independent January 5, 1997, The Independent on Sunday edition.

*** "ITC Guidance on Standards for Subtitling". 1999. ITC.

*** "The Trouble with English ...”. 2001. Language International 13(6): 6-7.

\section{Online References}

http://socialmarketing.org/archives/generations-xy-z-and-the-others/, 13

September 2018.

https://en.oxforddictionaries.com, 14 September 2018.

https://noriel.ro/joc-taboo-ghiceste-cuvantul, 14 September 2018.

https://support.amara.org/support/discussions/topics/28857, 21 June 2017.

https://www.coe.int/en/web/common-european-framework-referencelanguages/level-descriptions, 13 September 2018.

https://www.collinsdictionary.com/dictionary/english/yall, 14 September 2018. https://www.imdb.com/chart/toptv?ref_=tt_awd, 14 September 2018.

https://www.imdb.com/chart/toptv?ref_=tt_awd, 14 September 2018.

https://www.imdb.com/chart/tvmeter, 14 September 2018.

https://www.imdb.com/title/tt0185906/, 14 September 2018.

https://www.imdb.com/title/tt0208092/, 14 September 2018.

\section{Filmography}

Band of Brothers. 2001. TV Mini-Series. Dreamworks, HBO Films, Playtone and BBC. Directed by David Frankel, Mikael Salomon, Tom Hanks, David Leland, Richard Loncraine, David Nutter, Phul Alden Robinson, and Tony To. 